\title{
DIREITO E CIDADANIA: INSERÇÃO TRANSVERSAL DE TEMAS JURÍDICOS EM DISCIPLINAS ESCOLARES NO ENSINO MÉDIO
}

Laura Judith de Jesus Gama Universidade Estadual do Maranhão lauragama18@yahoo.com.br

Rodrigo Otávio Bastos Silva Raposo Universidade Estadual do Maranhão rodrigobastosraposo@hotmail.com

\section{Resumo}

Pesquisa-se metodologias lúdicas e eficazes para inserção transversal de conhecimento jurídico em escola do ensino médio. Indaga-se acerca de qual a melhor forma de conduzir as atividades de modo que se avalie a viabilidade e os benefícios da transversalidade ou da criação de disciplinas jurídicas na grade curricular. Diante do problema, constata-se a viabilidade jurídica e pedagógica da proposta e suas consequências positivas. A abordagem por meio de dinâmicas e discussões interessantes propicia a compreensão do conteúdo escolar sob uma nova ótica que mescla e harmoniza os conhecimentos de modo que se otimiza o aprendizado em sala de aula. Destaca-se que a discussão de questões jurídicas deve ser incluída entre os conteúdos obrigatórios do Ensino Médio, uma vez que não é só um fator de inclusão social, mas também de promoção da cidadania.

Palavras-chave: Educação. Direito. Cidadania.

\section{LAW AND CITIZENSHIP: ANALYSIS AND PERSPECTIVE ON CROSS-CUTTING LEGAL ISSUES IN HIGH SCHOOL DISCIPLINES}

\begin{abstract}
We are looking for playful and effective methodologies for transversal insertion of legal knowledge in high school. It is inquired about how best to conduct the activities in order to assess the feasibility and benefits of transversality or the creation of legal disciplines in the curriculum. Faced with the problem, the legal and pedagogical feasibility of the proposal and its positive consequences are confirmed. The approach through dynamics and interesting discussions facilitates the understanding of the school content under a new perspective that mixes and harmonizes the knowledge so that the learning in the classroom is optimized. It should be emphasized that the discussion of legal issues should be included among the compulsory contents of High School, since it is not only a factor of social inclusion, but also of promoting citizenship.

Keywords: Education. Law. Citizenship.

\section{DERECHO Y CIUDADANÍA: INSERCIÓN TRANSVERSAL DE TEMAS JURÍDICOS EN LAS DISCIPLINAS DE LA ESCUELA SECUNDARIA}

\section{Resumen}

Se busca metodologías lúdicas y eficaces para inserción transversal de conocimiento jurídico en la escuela de secundaria. Se indaga acerca de cuál es la mejor forma de conducir las actividades de modo que se evalúe la viabilidad y los beneficios de la transversalidad o de la creación de disciplinas jurídicas en la parrilla curricular. Ante el problema, se constata la viabilidad jurídica y pedagógica de la propuesta y sus consecuencias positivas. El enfoque por medio de dinámicas y discusiones interesantes propicia la comprensión del contenido escolar bajo una nueva óptica que mezcla y armoniza los conocimientos de modo que se optimiza el aprendizaje en el aula. Se destaca que la discusión de cuestiones jurídicas debe ser incluida entre los contenidos obligatorios de la Enseñanza Media, ya que no es sólo un factor de inclusión social, sino también de promoción de la ciudadanía.

Palavras clave: Educación. Derecho. La ciudadanía. 
Direito e cidadania: inserção transversal de temas jurídicos em disciplinas escolares no ensino médio

\title{
INTRODUÇÃO
}

Esse relato de experiência mostra um pouco das atividades realizadas e levadas a efeito por estudantes do Curso de Direito da Universidade Estadual do Maranhão no Centro de Ensino Manoel Beckman, em São Luís do Maranhão.

O presente tema torna-se importante em razão da possibilidade do maior entendimento do objeto de estudo por meio da inserção do direito de forma transversal nas disciplinas escolares através da análise do princípio fundamental implícito de acesso à cidadania presente no ordenamento jurídico ${ }^{1}$ brasileiro, segundo Silva (Silva, apud. Mazzuoli, 2001, pág. 17) a cidadania:

\begin{abstract}
"consiste na consciência de pertinência à sociedade estatal como titular dos direitos fundamentais, da dignidade como pessoa humana, da integração participativa no processo do poder, com a igual consciência de que essa situação subjetiva envolve também deveres de respeito à dignidade do outro e de contribuir para o aperfeiçoamento de todos".
\end{abstract}

Diante disso, tem-se em vista que a cidadania só pode ser exercida quando o indivíduo compreende minimamente a estrutura de normas que ordenam o Estado e a sociedade em que ele vive. Por isso, é dever do próprio Estado, em uma democracia, agir para disseminar o conhecimento do direito, imprescindível à construção de uma sociedade participativa. A democratização do conhecimento jurídico assegura que a sociedade de amanhã seja melhor do que a de hoje e não há dúvida que esta evolução histórica desencadeará uma reconstrução social. Dessa forma, as discussões sobre temas jurídicos têm o intuito de esclarecer aos jovens sobre seus direitos e deveres possibilitando que os mesmos não sejam cerceados por falta de conhecimento e possam transmitir tais conhecimentos às suas famílias e comunidade.

A problemática explorada no desenvolvimento desse trabalho gira em torno do questionamento do proveito e da viabilidade da inserção de temas jurídicos pertinentes ao desenvolvimento da cidadania de maneira transversal nas disciplinas escolares do Ensino Médio. As hipóteses levantadas dizem respeito a abertura e possibilidade de inserção dos mesmos no contexto legislativo de forma transversal, quais são os benefícios e qual a caracterização da medida legislativa ou administrativa necessária à introdução dos temas jurídicos na forma proposta.

\footnotetext{
${ }^{1}$ Esse contexto de normas costuma ser chamado de "ordenamento". E será bom observarmos, desde já, que a palavra "direito", entre seus vários sentidos, tem também o de "ordenamento jurídico", por exemplo, nas expressões "Direito romano", "Direito canônico", "Direito italiano" [“Direito brasileiro"], etc. [...] seria o contexto de produção normativa. E englobaria, portanto, não apenas as regras jurídicas por si, mas também as técnicas de produção e de integração das normas jurídicas de diferentes áreas do Direito.

BOBBIO, Norberto. Teoria do ordenamento jurídico. 6. ed. Brasília: Editora Universidade de Brasília, 1995, p. 19.
} 
Direito e cidadania: inserção transversal de temas jurídicos em disciplinas escolares no ensino médio

Tudo teve início quando alguns alunos, acadêmicos do curso de Direito-Bacharelado da Universidade Estadual de Maranhão, manifestaram interesse de desenvolver uma atividade além da sala de aula, com menos teoria e mais pragmatismo ${ }^{2}$ que pudesse ter algum impacto na vida das pessoas. Inquietava-os o fato do ensino do direito na universidade ser tão distante da vida da maioria das pessoas. Também incomodava o fato do direito ensinado ser tão distinto do direito praticado no dia-a-dia da vida de estagiário e aluno.

Após algumas discussões, tomou forma a ideia de atuar em uma escola, com alunos do ensino médio, nas proximidades da residência de um dos estudantes. Facilitava a execução da iniciativa: a familiaridade com a vizinhança e com a escola. Ficou decidido que a ação consistiria em levar conteúdos jurídicos aos estudantes, contribuindo para que eles ingressassem no universo da cidadania por meio da ciência de seus direitos e obrigações.

No entanto, após essa deliberação aparentemente simples, deparou-se com um primeiro obstáculo, pois, no grupo, ninguém possuía experiência com a educação de jovens, a não ser como destinatários dessa educação e, em geral, destinatários relativamente relutantes frente a muitos conteúdos pouco significativos.

Para enfrentar essa primeira dificuldade, procurou-se conhecer um pouco mais o trabalho de Paulo Freire, buscando ali alguma inspiração. A ideia mostrou-se fecunda, pois dos diálogos travados no contexto da proposta de educação freireana, percebeu-se que as atividades realizadas na escola pela equipe de estudantes teriam que ser significativas para os alunos e, mais do que isso, teria que permitir aos estudantes um certo protagonismo na definição dos conteúdos a serem trabalhados.

No primeiro momento, foi ofertado o acesso a duas turmas de alunos do $2^{\circ}$ ano do Ensino médio. $\mathrm{Na}$ opinião da Diretora da escola, os alunos do $1^{\circ}$ ano eram ainda muito imaturos, ao passo que os alunos do $3^{\circ}$ estavam priorizando a realização do ENEM. Foi curioso perceber que essa definição por parte da escola, em que havia muita gentileza e boa vontade para com nosso trabalho, era cheia daquela visão, por vezes criticada, de que os estudantes são objeto do processo educacional e não um de seus atores. Assim, tudo é escolhido por eles, nada lhes pergunta.

De todo modo, com o acesso nessas turmas, foi definido um calendário de visitas que não atrapalhasse de forma demasiada a condução normal da disciplina que nos cedia os horários. No primeiro encontro, a decisão foi fazer uma dinâmica em torno do que os alunos pensavam sobre

\footnotetext{
${ }^{2} \mathrm{O}$ que considera a utilização prática em oposição à teoria; análise das coisas através de uma abordagem pragmática: não há pragmatismo político.

DICIO. Significado de Pragmatismo. Disponível em: $<<$ https://www.dicio.com.br/pragmatismo/ $>>$. Acesso em: 25 Mar. 2019
} 
Direito e cidadania: inserção transversal de temas jurídicos em disciplinas escolares no ensino médio

o direito, sobre as leis, e que questões desse universo lhes despertavam atenção e curiosidade. Em grupos, eles discutiram e assinalaram os temas de maior interesse.

Foi com base nesse primeiro apanhado que foram definidos os temas das primeiras oficinas, ao mesmo tempo a equipe procurava se informar sobre técnicas didáticas, dinâmicas e participativas. Quanto à metodologia utilizada foi realizada uma análise legislativa referente a educação, seja, por meio de pesquisa documental: fichamento, comparativo de leis específicas; pesquisa bibliográfica e exploratória de livros metodológicos e teóricos, tais como "A pedagogia do Oprimido" do autor Paulo Freire, bem como pesquisa explicativa em busca de proporcionar maior familiaridade com a temática e com intuito de torná-lo explícito ou de construir hipóteses e identificar os fatores que determinam ou contribuem para a ocorrência dos fenômenos por meio da análise da história dos planos educacionais, funcionamento da educação e outros instrumentos legais, quais sejam o Plano Nacional de Educação 2014-2024 (PNE), Lei de Diretrizes e Bases da Educação Nacional de 1996 e artigos presentes na Constituição Federal sobre a educação e suas previsões principiológicas. Havia um certo temor de que, no momento das discussões, os estudantes se dispersassem ou não aceitassem participar das atividades.

A prática, no entanto, superou as expectativas. Não se sabe ao certo se o fato de terem escolhido os assuntos, ou o fato de se trabalhar os conteúdos de maneira lúdica, ou simplesmente o fato de estarem fazendo algo diferente no horário da aula, ocasionou um nível de interesse e participação que tornou o trabalho relativamente fácil. Ao contrário do que se imaginou a princípio, os estudantes das turmas do segundo ano tinham muitas perguntas, comentários e opiniões sobre o direito e seu impacto em suas vidas.

É a história dessa experiência que será contada a seguir.

\section{VIABILIDADE DA ABORDAGEM TRANSVERSAL DE TEMAS JURÍDICOS NAS DISCIPLINAS ESCOLARES}

A educação é tanto um mecanismo de desenvolvimento pessoal do cidadão, como da própria sociedade em que é inserido, o que reforça a percepção de que o Estado tem o dever de dar acesso à população ao entendimento jurídico para que esta se aproprie de seus direitos e obrigações e não permaneça como simples objeto das normas.

Diante disso, ao contemplar temas relevantes do direito, a educação constitui um fator importante na construção de uma mentalidade cidadã, pois a informação - neste caso, a informação sobre o direito - é fundamental para superar limites e permite formar conhecimento efetivo e eficaz para a vida (cf. FARIAS, 2007). Tanto a Constituição Federal de 1988, em seu art. 6, quanto a Lei de Diretrizes e Bases da Educação Nacional (Lei no 9.394 de 20 de dezembro de 
Direito e cidadania: inserção transversal de temas jurídicos em disciplinas escolares no ensino médio

1996) abordam a educação como instrumento para o processo formativo em diversos âmbitos na vida do ser humano, como na vida familiar, na convivência humana, no trabalho, nas instituições de ensino e pesquisa, nos movimentos sociais, organizações da sociedade civil e nas manifestações. A introdução e abordagem do direito como tema transversal teria sua previsão legal na área de conhecimento de ciências humanas e sociais aplicadas e formação técnica profissional previstos nos art. 3, IV e art. 4, V, respectivamente, da mencionada Lei. Ainda, podese identificar na mesma lei tal possibilidade no art. $1^{\circ}$ e $2^{\circ}$ quando afirma que:

A educação abrange os processos formativos que se desenvolvem na vida familiar, na convivência humana, no trabalho, nas instituições de ensino e pesquisa, nos movimentos sociais e organizações da sociedade civil e nas manifestações culturais, ratificando que a educação escolar deverá se vincular ao mundo do trabalho e à prática social.

Tal dispositivo apregoa que a escola é um meio de preparação e valorização da experiência extraescolar, em que se faz menção à liberdade, a tolerância e a vinculação da educação escolar às práticas sociais. Segundo Tezoto (2011, p.6) a "educação escolar é base constitutiva na formação do ser humano, e está presente também na luta cotidiana dos cidadãos por direitos individuais e coletivos. E é nesta luta que se apreende o compromisso com o respeito pelos direitos de outras pessoas, portanto, com seus deveres". Diante disso, analisa-se que a aplicação dessas diretrizes em sala de aula deveria impreterivelmente passar pelo contato com a Constituição Federal e outras legislações infraconstitucionais ${ }^{3}$ pertinentes a realidade dos alunos.

Tem-se como objetivo principal a formação integral do aluno, de maneira a adotar um trabalho voltado para a construção de seu projeto de vida e para sua formação nos aspectos físicos, cognitivos e socioemocionais conforme reza o art. $3, \int 7^{\circ}$ da mesma lei $n^{\circ} 9.394$ de 20 de dezembro de 1996. O legislador deixa livre a forma de organização dessas áreas e das suas respectivas competências e habilidades de acordo com critérios estabelecidos por cada sistema de ensino. Diante disso, para que o ensino jurídico seja incorporado por via transversal as disciplinas lecionadas, dispensa-se alterações legislativas, haja vista se identificar a permissividade legal para tanto, ainda que de forma genérica, na própria LDB (Lei nº 9.394 de 20 de dezembro de 1996):

Art. 26 - Os currículos da educação infantil, do ensino fundamental e do ensino médio devem ter base nacional comum, a ser complementada, em cada sistema de ensino e em cada estabelecimento escolar, por uma parte diversificada, exigida pelas características regionais e locais da sociedade, da cultura, da economia e dos educandos.

\footnotetext{
${ }^{3}$ É a norma, preceito, regramento, regulamento e lei que estão hierarquicamente abaixo da Constituição Federal. A Constituição Federal é considerada a Lei Maior do Estado, e as demais normas jurídicas são consideradas infraconstitucionais, pois são inferiores às regras previstas na Constituição. LENZA, Pedro. Direito

Constitucional Esquematizado. 22. ed. São Paulo: Editora Método, 2018.
} 
Direito e cidadania: inserção transversal de temas jurídicos em disciplinas escolares no ensino médio

Quanto ao conteúdo curricular a que se refere o artigo em epígrafe, observa-se uma noção também genérica quando afirma que "I $1^{\circ}$ os currículos a que se refere o caput devem abranger, obrigatoriamente, o estudo da língua portuguesa e da matemática, o conhecimento do mundo físico e natural e da realidade social e política, especialmente do Brasil”. Com base no exposto, pode-se observar a importância atribuída ao estudo das disciplinas português, matemática e o conhecimento do mundo físico, vistas como obrigatórias, entretanto não se restringe somente a elas, apontando como também essenciais a compreensão da realidade social e política, em especial do Brasil.

As atividades de extensão demonstraram não só a viabilidade legislativa, mas também a viabilidade prático social em que a escola tem um papel essencial na formação de cidadãos conscientes e aptos, que interiorizam seu papel, não só enquanto indivíduos, mas enquanto seres sociais, conhecendo seus direitos e obrigações, conhecendo o ordenamento jurídico do seu país e o seu funcionamento.

\section{DESCRIÇÃO DAS ATIVIDADES REALIZADAS}

O projeto em questão foi realizado na escola pública estadual chamada Centro de Ensino Manoel Beckman localizada à rua 51, s/n, Conjunto Bequimão, fundada no ano de 1998, pelo governador do Maranhão, João Castelo Ribeiro Gonçalves, para atender à demanda dos alunos do ensino fundamental do Conjunto Bequimão e entorno. Possui atualmente as seguintes modalidades: Ensino Fundamental, de $5^{\mathrm{a}}$ a $8^{\mathrm{a}}$ séries com 381 alunos, funcionando no turno vespertino; Educação Especial, turno vespertino com o total de 12 alunos especiais, Ensino Médio, $1^{\text {a a }} 3^{\text {a }}$ séries com 889 alunos no total, funcionando nos turnos matutino e noturno, educação de Jovens e Adultos - EJA, na modalidade Ensino Médio, no turno noturno com 225 alunos no total.

\section{Preparação da equipe e definição de estratégias}

Nas primeiras reuniões, especificamente em Setembro de 2014, percebemos que a prática acadêmica no curso de direito, os modos de ensinar e aprender, constituíam por si mesmos um obstáculo para a democratização do conhecimento jurídico, o empoderamento e a emancipação dos destinatários da ordem jurídica. 
Direito e cidadania: inserção transversal de temas jurídicos em disciplinas escolares no ensino médio

Nos primeiros contatos com a escola ficaram acertadas datas, professores colaboradores e turmas a trabalhar. Havia na equipe ansiedade para começar as atividades e o temor de que uma preparação mais prolongada acabasse por afogar a realização do projeto no mar de pressupostos que começava-se a entrever. Então, apesar das limitações e do fato da equipe não estar adequadamente preparada para a aplicação da metodologia de temas geradores, seguiu-se em frente.

Percebemos que boa parte do vocabulário com o qual se estava acostumado a descrever o direito não faz nenhum sentido para aqueles que não frequentam os bancos do curso e não passaram pelo processo de aculturação ao qual são forçados os estudantes de direito desde os primeiros períodos da faculdade.

A visão da equipe responsável pelo desenvolvimento do projeto mostrou-se posteriormente compatível com a lição de Freire:

\footnotetext{
Nosso papel não é falar ao povo sobre a nossa visão do mundo, ou tentar impô-la a ele, mas dialogar com ele sobre a sua e a nossa. Temos de estar convencidos de que a sua visão do mundo, que se manifesta nas várias formas de sua ação, reflete a sua situação no mundo, em que se constitui. A ação educativa e política não pode prescindir do conhecimento crítico dessa situação, sob pena de se fazer "bancária" ou de pregar no deserto (FREIRE, 1983, p. 102).
}

Essa constatação expôs a necessidade de refletir sobre o efeito do ensino jurídico em professores, alunos e profissionais do direito, levando-os a adquirir uma linguagem ritualizada que, se por um lado parece natural e própria ao labor profissional do jurista, por outro, torna a fala e o agir, dos que estão imersos nesse mundo do Direito, estranhos para as outras pessoas.

Do mesmo modo, essa situação revelou que seria necessário adequar a abordagem da equipe e também suscitou a hipótese de que a maneira como está estruturada a educação jurídica nas universidades é um dos fatores do estranhamento entre o mundo do direito e a vida das pessoas.

Assim, naquele momento inicial, ficou decido estudar as reflexões sobre educação e a proposta metodológica de Paulo Freire, bem como buscar contato com outras pessoas e entidades que já tivessem vivenciado experiências de educação popular.

Em Outubro de 2014 a equipe extensionista assistiu ao documentário sobre a vida e a obra de Paulo Freire (FREIRE, Paulo. Contemporâneo. TV ESCOLA, 2006). O principal achado resultante da análise do documentário foi a importância da utilização dos temas geradores no ensino e principalmente, no aprendizado dos educandos, pois possibilita que o aluno compreenda o contexto em que está inserido e sua realidade. Sugerir e criar situações de vida comuns e significativas para a comunidade e o meio em que se atua, colocando-os diante de situações e 
Direito e cidadania: inserção transversal de temas jurídicos em disciplinas escolares no ensino médio

desafios, desenvolvendo assim seu pensamento crítico na busca de novos conhecimentos através da leitura e releitura do mundo.

Segundo Freire, o conteúdo programático da educação não pode ser definido exclusivamente pelos educadores, sendo necessário buscá-lo na realidade onde se relacionam os educadores e o povo, pois é nela que se constituem a sua linguagem e o seu pensar. Essa busca “inaugura o diálogo da educação como prática da liberdade. É o momento em que se realiza a investigação do que chamamos de universo temático do povo ou o conjunto de seus temas geradores” (FREIRE, 1983, p. 102).

Arelaro (2015, pág.02), comentarista e admiradora de várias obras de Paulo Freire afirma que sua obra apresenta um amplo acervo teórico com reflexões que apontam para a importância de uma educação que parta das necessidades populares como prática de liberdade e de emancipação das pessoas, e não de categorias abstratas, isto é ele procurava partir do concreto, do conhecimento já existente. Para ele, a educação requer, de forma permanente: o cultivo da curiosidade; as práticas horizontais mediadas pelo diálogo; os atos de leitura do mundo e sua problematização; a ampliação do conhecimento que cada um detém sobre o mundo problematizado; a interligação dos conteúdos apreendidos; e o compartilhamento do mundo conhecido a partir do processo de construção e reconstrução do conhecimento.

Tendo isso em mente, e com o propósito de preparação da equipe para desenvolver o projeto, ainda no mês de Outubro, foi realizado a leitura e discussão de artigos de periódicos sobre extensão universitária tomando como base experiências positivas e negativas para o desenvolvimento do projeto onde se encontrou exemplos e tipos de metodologias lúdicas para serem desenvolvidas com os alunos, tais como jogo da forca, cruzadinha, jogo da memória etc.

Paralelamente ao projeto, foram realizadas visitas a grupos de extensão já constituídos e atuantes como o Núcleo de Assessoria Jurídica Popular Negro Cosme, do Curso de Direito da Universidade Federal do Maranhão em que se pode obter conhecimentos de metodologias de como abordar temas geradores de forma lúdica e prática, com intuito de levantar discussões pertinentes a realidade daquele público alvo. Nesse momento, foram esclarecidas as dúvidas e mostrado métodos de como fazer exposição no encontro de frases de impacto e frases populares, tais como "Bandido bom é bandido morto", "Os políticos são todos iguais", as quais por vezes são preconceituosas e generalizadoras, fazendo o público-alvo refletir sobre a temática em questão.

Visitou-se também a Ordem dos Advogados do Brasil, Seccional do Maranhão, onde se pode conhecer como era a atuação deste junto a comunidades vulneráveis e jovens, foram recolhidas informações de como eram feitos os projetos das comissões e como se organizavam 
Direito e cidadania: inserção transversal de temas jurídicos em disciplinas escolares no ensino médio

para realizar as atividades. Verificou-se também as questões de provas do Exame Nacional do Ensino Médio relativas à temática dos Direitos Humanos em que foi constatado que as questões que haviam uma certa ligação com direito eram as que envolviam sociologia, português, história e filosofia, o que posteriormente foi utilizado como parâmetro para embasamento, fundamentação e associação de conteúdos nas próprias palestras elaboradas.

O documentário (DEWEY, John. TV Escola, 2004) também foi explorado, foram realizadas leituras de artigos sobre esse filósofo da educação crítica conhecido por John Dewey. Onde se continuou a discussão sobre a filosofia da educação crítica embasada nas teorias do filósofo John Dewey defensor da Escola Nova partindo dos pressupostos teóricos os quais defendem que toda análise do problema que é feita de forma coletiva tende-se a cair no erro. Discutiu-se as dicotomias da educação tendo como vertente a crítica e a reflexão. Assistimos ao documentário falando das teorias de John Dewey.

Mais adiante pode-se perceber que essa insubordinação às condições externas não é incoerente com a prática de uma educação libertadora, como ensina Freire:

\footnotetext{
Se a vida do animal se dá em um suporte atemporal, plano, igual, a existência dos homens se dá no mundo que eles recriam e transformam incessantemente. Se, na vida do animal, o aqui não é mais que um "habitat" ao qual ele "contacta", na existência dos homens o aqui não é somente um espaço físico, mas também um espaço histórico.

Para o animal, rigorosamente, não há um aqui, um agora, um ali, um amanhã, um ontem, porque, carecendo da consciência de si, seu dever é uma determinação total. Não é possível ao animal sobrepassar os limites impostos pelo aqui, pelo agora, ou pelo ali.

Os homens, pelo contrário, porque são consciência de si e, assim, consciência do mundo, porque são um "corpo consciente", vivem uma relação dialética entre os condicionamentos e sua liberdade (FREIRE, 1983, p. 105-106).
}

Desta forma, justificava-se a decisão de agir, mesmo sem uma preparação adequada, e de refletir sobre essa ação, tanto no intuito de aperfeiçoar a nossa ação junto à área de trabalho que definimos, como com o propósito de adquirir uma compreensão mais rica da metodologia que pretendíamos aplicar.

Fixemo-nos, contudo, apenas na investigação dos 'temas geradores' ou da temática significativa. Delimitada a área em que se vai trabalhar, conhecida através de fontes secundárias, começam os investigadores a primeira etapa da investigação (FREIRE, 1983, p. 121).

Decidimos então iniciar a primeira etapa de investigação dos temas geradores no mês de Novembro de 2014. 
Direito e cidadania: inserção transversal de temas jurídicos em disciplinas escolares no ensino médio

\section{Os primeiros encontros}

No primeiro encontro, após explicar o propósito da presença da equipe na escola, pedimos aos alunos que se reunissem em pequenos grupos de 6 ou 7 alunos e indicassem que assuntos do direito seriam interessantes para discutirmos em nossos próximos encontros.

Após, realizamos também uma pesquisa para sondar os temas escolhidos, de forma qualitativa, que primeiro poderiam ser abordados nos próximos encontros. Percebeu-se a afinidade com temas relacionados com acontecimentos cotidianos, experiências vividas e dúvidas não sanadas, tais como direito do trabalhador, violência doméstica, diminuição da maioridade penal, racismo e direitos da mulher. Como haviam temas polêmicos e denunciativos de realidades de vida dos próprios alunos não chamamos os alunos para justificar suas escolhas. Após avaliamos os temas citados e fizemos uma tabela analisando de forma quantitativa e qualificativa cada tema, conforme mostra a figura abaixo.

\begin{tabular}{|l|c|c|c|c|c|c|}
\hline \multirow{2}{*}{ TEMAS } & \multicolumn{5}{|c|}{ CONCEITOS AVALIATIVOS } \\
\cline { 2 - 7 } & \multicolumn{2}{|c|}{ Ruim } & \multicolumn{2}{c|}{ Bom } & \multicolumn{2}{c|}{ Muito Bom } \\
\hline Reconhecimento de Paternidade: & 16 & $31 \%$ & 11 & $22 \%$ & 25 & $49 \%$ \\
\hline Direito à pensão: & 12 & $24 \%$ & 17 & $33 \%$ & 22 & $43 \%$ \\
\hline Quem são os responsáveis pelos filhos na ausência dos pais?: & 12 & $24 \%$ & 18 & $35 \%$ & 18 & $35 \%$ \\
\hline Separação dos pais: & 19 & $37 \%$ & 16 & $31 \%$ & 16 & $31 \%$ \\
\hline Assistência às fámilias que tem dependentes químicos: & 12 & $24 \%$ & 18 & $35 \%$ & 21 & $41 \%$ \\
\hline Violência Doméstica: & 6 & $12 \%$ & 13 & $25 \%$ & 28 & $55 \%$ \\
\hline Homofobia e direito dos homossexuais: & 18 & $35 \%$ & 14 & $27 \%$ & 20 & $39 \%$ \\
\hline Direito do trabalhador: & 4 & $8 \%$ & 18 & $35 \%$ & 29 & $57 \%$ \\
\hline Direitos e deveres dos desempregados: & 19 & $37 \%$ & 15 & $29 \%$ & 17 & $33 \%$ \\
\hline Direito Ambiental: & 10 & $20 \%$ & 22 & $43 \%$ & 20 & $39 \%$ \\
\hline Direito do consumidor: & 12 & $24 \%$ & 14 & $27 \%$ & 25 & $49 \%$ \\
\hline Direito dos estagiários: & 9 & $18 \%$ & 23 & $45 \%$ & 19 & $37 \%$ \\
\hline Racismo: & 7 & $14 \%$ & 12 & $24 \%$ & 32 & $63 \%$ \\
\hline Meios publicos para se reivindicar direitos: & 11 & $22 \%$ & 19 & $37 \%$ & 20 & $39 \%$ \\
\hline Direitos da mulher: & 7 & $14 \%$ & 15 & $29 \%$ & 31 & $61 \%$ \\
\hline Diminuição da maioridade penal: & 8 & $16 \%$ & 12 & $24 \%$ & 28 & $55 \%$ \\
\hline Legalização das drogas para fins medicianais e para consumo: & 13 & $25 \%$ & 16 & $31 \%$ & 21 & $41 \%$ \\
\hline Critérios para reajuste das tarifas dos transportes: & 9 & $18 \%$ & 22 & $43 \%$ & 20 & $39 \%$ \\
\hline Candidatura a cargos políticos eletivos: & 17 & $33 \%$ & 21 & $41 \%$ & 14 & $27 \%$ \\
\hline
\end{tabular}

Tabela 1 - Temas geradores

O primeiro tema que abordamos no projeto, especificamente no mês de Dezembro de 2014 foi o conceito de autonomia como capacidade de autodeterminação, em que permite o pensar e o agir por conta própria. Sem a autonomia cai-se no fatalismo ${ }^{4}$. Fatalismo porque o

\footnotetext{
${ }^{4} \mathrm{O}$ termo fatalismo é formado a partir da raiz latina fatum, que significa "destino". Portanto, o "fatalista" acredita na necessidade de que a negação da liberdade seja irremediavelmente imposta ao ser humano. No sentido comum, o fatalismo refere-se a uma crença no determinismo dos acontecimentos, direcionado por causas independentes da vontade humana, se esse determinismo vem de forças sobrenaturais como Deus, leis naturais, meio ambiente ou as experiências adquiridas no passado. EDUCALINGO. Fatalismo. Disponível em: $<<$ https://educalingo.com/pt/dic-es/fatalismo>>. Acesso em: 25 Mar. 2019
} 
Direito e cidadania: inserção transversal de temas jurídicos em disciplinas escolares no ensino médio

sujeito não seria responsável pelas suas ações e pelo seu destino, ele seria fruto de um determinismo sociocultural.

Afirmar a autonomia é justamente afirmar a liberdade, assumindo o centro das próprias escolhas, apesar de haver condicionantes empíricas. Se o sujeito é livre, e não fruto de um determinismo, pode se falar em ética ao tornar-se responsável pelas próprias ações e sonhar com um mundo melhor. Para Freire, também é uma questão ética respeitar a autonomia dos educandos, de forma que é indissociável o ensino dos conteúdos com a formação ética.

Aliada a esse estudo fundamentou-se também em aspectos filosóficos, os quais apontam que a busca pela autonomia através da emancipação foi objeto do Iluminismo e compõe o projeto da modernidade. Sem entrar no mérito dos movimentos históricos, pecando por não contextualizar devidamente a questão, Immanuel Kant tratou dessa temática no opúsculo “Resposta à pergunta: o que é 'esclarecimento'?”, no qual realizou a seguinte reflexão: "esclarecimento é a saída do homem de sua menoridade, da qual ele próprio é culpado. A menoridade é a incapacidade de fazer uso de seu próprio entendimento sem a direção de outro indivíduo. [...] não tenho necessidade de pensar, quando posso simplesmente pagar; outros se encarregarão em meu lugar dos negócios desagradáveis.” (KANT, 2005. p. 63-64). O que levounos a reflexão sobre a inércia do reagir as situações e mazelas sociais, perpetuando desta forma o comodismo de repassar responsabilidades a outrem e se ausentar do poder de escolha.

Diante disso, viu-se necessário abordar a importância da participação, reflexão e posicionamento perante acontecimentos cotidianos dentro ou não da sua realidade. Para Freire, a autonomia é uma característica diferenciada na educação, sendo condição necessária para o desenvolvimento e definição de outras capacidades. Assim, na especialidade do ensino jurídico, a autonomia é condição para o desenvolvimento da reflexão crítica, formação humanística e outros elementos que compõem o perfil do aluno que deve ser formado.

Esta não é uma característica de desenvolvimento rápido. Deve ser trabalhada constantemente, no ensino fundamental e médio. Nas palavras de Freire: “[...] ninguém amadurece de repente, aos 25 anos. A gente vai amadurecendo todo dia, ou não. A autonomia, enquanto amadurecimento do ser para si, é processo, é vir a ser.” (FREIRE, 1983, p. 107) O desenvolvimento da autonomia é paulatino, devendo perpassar por toda a formação discente.

Uma das necessidades de grande importância metodológica foi a abordagem do Direito aplicado, uma das estratégias que permite o fomento da autonomia é a aprendizagem baseada em problemas, adaptando a linguagem ao público alvo e proporcionando um efeito prático na vida do mesmo. Esta prática é centrada no desenvolvimento de capacidades de aprendizagem dos alunos através de discussões em grupo. Em linhas gerais, escolheu-se temas que foram debatidos 
Direito e cidadania: inserção transversal de temas jurídicos em disciplinas escolares no ensino médio

ao longo dos encontros, promovendo discussões em torno dos problemas, metodologia na qual o extensionista e equipe assumiram uma posição de orientadores das discussões, abandonando a sistemática de simples transmissão e memorização de conhecimentos.

$\mathrm{Na}$ aprendizagem baseada em problemas há amplo espaço para o diálogo. As discussões devem ser abertas para reflexões de todos e sempre dirigidas pelas coordenadas do extensionista. A estrutura do plano de ensino dos assuntos foi dividida entre uma parte dogmática ${ }^{5}$ e outra parte dedicada as discussões de temas atuais. O direito, pela sua própria natureza, está em constante mutação, tanto pela emanação de novas leis quanto pela interpretação jurisprudencial ${ }^{6}$. E nestas discussões atuais sobre os rumos do Direito todos são igualmente legitimados para propor interpretações e ideias acerca de um tema. Neste contexto, uma metodologia apta a incentivar a autonomia seria eleger e promover discussões em torno de um tema atual, como agora é a reforma do Código de Processo Civil, ou alguma questão de repercussão geral.

\section{O desenvolvimento das atividades}

Abordamos nos encontros do mês de Fevereiro de 2015 temas como: o direito de imagem analisando, assim, seu impacto com o progresso da comunicação, no contexto publicitário tendo como consequência a grande exposição da imagem, agregando a esta, dessa forma, expressivo valor econômico. Conceituou-se tal tema baseado nas doutrinas jurídicas ${ }^{7}$ e no Código Civil de 2002, como também as classificações pertinentes para o melhor entendimento do mesmo, no âmbito jurídico. Após, para consolidar o conhecimento, foi feito o estudo dos litígios jurídicos ${ }^{8}$ presentes no caso de violação ao direito de imagem e informação da atriz e apresentadora, Daniella Cicarelli, de forma aprofundada e de fácil entendimento por parte dos

\footnotetext{
${ }^{5}$ Estudo cientifico das normas e regras já postas ou vigentes. É o estudo sistemático do Direito Positivo. Aborda os problemas da aplicação Jurídica. Para Miguel Reale, é o "estudo sistemático das normas, ordenando-as segundo princípios e tendo em vista a sua aplicação". Pode haver, por exemplo, dogmática jurídica civil, penal, comercial, etc. DA SILVA, Marcos Luiz. Dogmática e Epistemologia Jurídica-AGU. Disponível em: $<<$ https://www.agu.gov.br/page/download/index/id/640103>>. Acesso em: 26 Mar. 2019

${ }^{6}$ Assim reza a doutrina de Paulo Nader: "Jurisprudência em sentido estrito: [...] conjunto de decisões uniformes, prolatadas pelos órgãos do Poder Judiciário, sobre uma determinada questão jurídica". JURID, Jornal. Sobre a hierarquia das leis no direito brasileiro. Disponível em: $<<$ https://www.jornaljurid.com.br/colunas/giseleleite/sobre-a-hierarquia-das-leis-no-direito-brasileiro>>. Acesso em: 26 Mar. 2019

${ }^{7}$ Doutrina jurídica é a reunião de ideias que são utilizadas como base para a formulação de teorias no âmbito jurídico e que seguem a regra onde, através de uma interpretação, é utilizado um padrão no exercício de uma determinada lei. DICIONÁRIOS, MEUS. Disponível em: <<https://www.meusdicionarios.com.br/doutrina $>>$. Acesso em: 26 Mar. 2019

${ }^{8}$ Litígio é sinônimo de lide, demanda. Trata-se da questão judicial, do conflito de pretensões que será discutido entre as partes na ação. É a disputa que será solucionada em juízo, a pendência que é submetida ao juiz para ser examinada. DIREITONET. Litígio. Disponível em:

$<<$ https://www.direitonet.com.br/dicionario/exibir/934/Litigio>>. Acesso em: 26 Mar. 2019
} 
Direito e cidadania: inserção transversal de temas jurídicos em disciplinas escolares no ensino médio

alunos. Estiveram presentes também no projeto no mês de Março os temas "Separação dos pais, direitos dos filhos; direito a pensão alimentícia", em que se esclareceu as diferentes formas de guarda dos filhos menores de idade, como é feita a escolha do genitor, quais critérios são levados em consideração nesses casos litigiosos, o conceito de pensão alimentícia e como é calculada de acordo com cada estrutura familiar, prisão por descumprimento do pagamento da pensão alimentícia, pensão a ex-cônjuge, visita impedida aos filhos e no final fez-se o estudo dos casos Alexandre Pato e Stefanne Brito e do jogador Romário.

Após a explanação em sala de aula acerca dos direitos da personalidade, direitos individuais e coletivos foi realizado a montagem de um mural no mês de Abril de 2015, no qual foram colocadas reportagens relacionadas com os direitos da personalidade, direitos individuais e coletivos onde foi feita associação entre cada reportagem e o direito respectivamente violado. Para a explanação e montagem do mural foram necessários dois encontros.

Simulamos o tribunal do júri no mês de Maio de 2015, em que identificou-se os operadores do direito participantes e suas atribuições, tais como juiz, promotor, testemunhas, júri, advogados etc. Onde foi encenado e julgado em sala de aula, com os próprios alunos contracenando, o caso adaptado da chapeuzinho vermelho e o lobo mau, em que identificou-se os crimes e violações praticadas pelo lobo mau em desfavor da chapeuzinho vermelho, aplicando-se maior parte do assunto abordado no decorrer do projeto, no caso em questão, como forma de fixação e aprendizagem para os alunos.

Realizamos o desenvolvimento de diversos tipos de jogos, como já mencionado anteriormente, tais como, o jogo da forca e a cruzadinha que foram utilizados para fixação de conhecimento após explanação dos tipos de direitos e garantias fundamentais e os direitos da personalidade, respectivamente, abordados em sala de aula no mês de Junho de 2015. No jogo da memória foram utilizados como peças, cartões informativos de atualizações e mudanças no ordenamento jurídico brasileiro de grande importância para os cidadãos encontrados e retirados do facebook oficial do Senado Federal.

Para que os alunos lessem e refletissem as informações e não apenas associassem as imagens, foi feita uma alteração substancial no jogo, sendo que as imagens dos pares das cartas eram as mesmas, mas as informações foram alteradas, em um cartão continha informações verídicas e em outro cartão com a mesma figura continha informações absurdas e inverídicas do mesmo tema. Desta forma, os alunos leram e refletiram sobre qual informação estava certa e com o acerto ganhavam algum doce ou bombom como brinde. Com a realização desse jogo da memória foi possível aumentar o conhecimento e ter uma percepção do direito em várias áreas de uma forma prática e lúdica. 
Direito e cidadania: inserção transversal de temas jurídicos em disciplinas escolares no ensino médio

Utilizamos como ferramentas alguns livros didáticos e lúdicos como direito penal ilustrado em quadrinhos da autora Denise Cardia Saraiva, o qual foi utilizado como material de preparação com diversos exemplos simples e práticos para explicação de assuntos do direito penal em sala de aula, o que também foi utilizado na execução do projeto.

No mês de Agosto de 2015 abordamos o tema que versa acerca dos vários tipos de família existentes na sociedade brasileira. $O$ encontro iniciou-se com a atividade cultural de um breve jogo em sala de aula, onde foi exposto na lousa branca em destaque, os tipos de família que seriam abordados no encontro e após colocamos as músicas que retratavam tipos diferentes de famílias e ao término de cada uma, o assunto e caracterização eram abordados. Ao final, ressaltamos a importância da tolerância e respeito na vida em sociedade, frisou-se que para a área jurídica pouco importa raça, etnia, cor ou religião, crédulo etc, para se formar uma família, mas tenta de diversas formas possíveis, por meio de resoluções e leis resguardar o direito à liberdade de cada pessoa escolher como e com quem quer constituir um vínculo familiar.

Realizou-se revisão bibliográfica no último mês do projeto, Setembro de 2015, onde analisamos o tema da educação popular e direito, lemos o livro Métodos de Ensino e Aprendizagem e a Dinamização das Aulas da autora Mary Rangel que foi de grande enriquecimento metodológico para o desenvolvimento de dinâmicas e criação de metodologias paralelas aos assuntos como a utilização de brincadeiras e jogos que fazem parte do dia-a-dia dos adolescentes.

\section{RESULTADOS E ANÁLISES}

Diante disso, pode-se concluir que as atividades realizadas foram de grande importância para o crescimento e enriquecimento intelectual dos alunos, visto que o direito é um mecanismo de mudança sócio e intelectual diante das mazelas e dificuldades que a sociedade perpassa podendo transformar mentalidades e o meio em que se vive. Mais que isso, as ações serviram para alterar a forma como os extensionistas percebem o direito em sua relação última com os seus destinatários e como estes estão afastados de qualquer protagonismo nesse universo.

As atividades extensionistas resultaram numa melhor percepção dos alunos, em relação ao olhar mais crítico da realidade, em que os mesmos são capazes de discutir com mais propriedade a respeito dos fatos que perpassam suas vidas diariamente, a conscientização da importância do conhecimento jurídico no âmbito social e educacional, o desenvolvimento das habilidades de argumentação e interpretação de casos cotidianos e suas devidas providências, bem como a ampliação do conhecimento jurídico e familiarização no manuseamento de material jurídico aprendendo a melhor forma de pesquisa desses matérias na internet como também sua função e 
Direito e cidadania: inserção transversal de temas jurídicos em disciplinas escolares no ensino médio

para qual público está direcionado. Com relação a interpretação, no início, foi um pouco impactante esse encontro dos alunos com a linguagem jurídica, pois esta é bem específica e possui termos próprios que somente com o tempo e prática pode-se entender e fixar. Mas como foram selecionados casos práticos e os assuntos mais próximos da realidade dos alunos, esse processo foi mais tranquilo, pois tudo que foi abordado, já fazia parte da vivência dos alunos, visto na televisão (jornais e outros meios de comunicação) ou visto alguém viver algo igual ou semelhante. O que possibilitou o desenvolvimento do projeto com interação e reconhecimento dos alunos no que estava sendo abordado em sala de aula.

Com isso, tornou-se possível fazer analogias com assuntos de disciplinas escolares, tais como sociologia, história e filosofia. O que possibilitou um certo esforço dos alunos de recapitularem assuntos e conceitos trabalhados em outro momento em sala de aula fixando, desta forma, mais ainda seu conhecimento nessas disciplinas. A capacidade de análise e reflexão foram os pontos chave do projeto, pois do início ao fim do projeto, pôde-se perceber um avanço significativo da argumentação, interação e reflexão dos temas abordados em sala de aula. Assuntos relacionados ao direito dos idosos, das pessoas portadoras de deficiência, da criança e do adolescente foram temas bastante abordados com o intuito de fomentar o exercício da cidadania e estimular o respeito e ajuda ao próximo.

Propiciou um maior envolvimento e aproximação da comunidade acadêmica no que tange as questões sociais, desenvolvendo um espírito crítico e de cidadania na equipe, estudantes e professores. Demonstrou-se a importância da conscientização do conhecimento jurídico no âmbito social e educacional aproximando os estudantes, comunidade e universidade no que tange a inclusão e integração por meio do conhecimento jurídico para a sociedade.

A experiência adquirida e formada a partir do projeto fomentado, traduziu-se no surgimento de estratégias de desenvolvimento do mesmo de forma prática, lúdica e clara. Analisou-se os êxitos, dificuldades e metodologias utilizadas em sala de aula e em cima disso foi construído o roteiro a ser seguido. Com relação às transformações ocorridas durante e após a realização do projeto, pode-se analisar que o melhor entendimento da realidade se deu, devido às situações cotidianas que geralmente apresentavam violações ao direito do cidadão e que passavam despercebidos diante da sociedade. Isso fez com que os alunos ficassem mais atentos e tivessem mais consciência dos próprios atos e das atitudes de terceiros. Pode-se observar também a melhoria no julgamento e reflexão das situações cotidianas pertinentes ao direito, o que muitas vezes eram vistas e tratadas de forma muito voltada ao senso comum o que direcionava para julgamentos já pré-determinados socialmente. 
Direito e cidadania: inserção transversal de temas jurídicos em disciplinas escolares no ensino médio

Durante o desenvolvimento encontramos mais algumas dificuldades, tais como: tivemos como barreira a linguagem jurídica, como já conhecida por ter características próprias e, por vezes de difícil entendimento, nos vimos obrigados a procurar maneiras e linguagens pertinentes ao dia-a-dia dos alunos. O que gradativamente foi melhorando e se aprimorando com o passar do tempo.

Pode-se também fazer uma análise das dificuldades operacionais para a otimização do projeto supracitado, quais sejam o tempo de aula de 40 minutos que limitou e fez com que os assuntos fossem desenvolvidos de forma apressada e mais precisa, não podendo explorar, de forma significativa, a troca e a construção do conhecimento entre aluno e pesquisador. Isso impossibilitou de saber mais a fundo como pensavam os alunos antes do desenvolvimento do projeto. Muitos temas foram questionados, mas devido ao tempo limitado não se pôde valorizar tais dúvidas que em sua maioria não foram respondidas de forma aprofundada. Havia um nítido conflito em explorar o assunto programado, tirar as dúvidas pertinentes ao assunto ou explorar e valorizar os diversos questionamentos que por muitas vezes atingiam grandes proporções e iam muito além do que estava sendo abordado. A exemplo dessas indagações, os alunos se perguntavam para onde ia o dinheiro das multas penais, em que eram aplicadas; qual a diferença entre voto nulo e voto em branco; quando a pessoa era condenada ela iria direto para cadeia ou não etc. Para amarrar o assunto e fugir um pouco do modelo bancário de aula, os encontros foram desenvolvidos em cima de casos práticos jurídicos, os quais abordavam assuntos específicos e soluções mais simples de se analisar juridicamente, nada que fosse impossível de interpretar.

Outro desafio foi de encontrar temas que fossem pertinentes para a vida, momento e contexto social desses alunos. O que através de pesquisas e muita leitura de artigos de experiência conseguimos filtrar e selecionar alguns temas que foram associados aos temas sugeridos por os próprios alunos na pesquisa qualitativa de temas geradores realizada.

Dentre os fatores de inovação da experiência, é possível destacar o maior envolvimento e entendimento de assuntos pertinentes ao âmbito jurídico e dessa forma a interação direta e constante dos alunos e professores com o direito, o que passou a ser ferramenta de trabalho e de diálogo para o surgimento de novas formas de abordagens e metodologias. A experiência obtida no projeto no Centro de Ensino Manoel Beckman no ensino médio, propiciou a adaptação a diversas realidades e contextos realizando a interação entre agentes da educação com a comunidade acadêmica e local. Teve grande impacto na escola quanto na vida dos alunos que pelo projeto passaram. Observou-se o crescente reconhecimento do exercício dos direitos e dos deveres dos alunos no seu meio social. Evidenciou-se a realidade que os educandos estão 
Direito e cidadania: inserção transversal de temas jurídicos em disciplinas escolares no ensino médio

inseridos, sintonizando-os com a sociedade permitindo-se a compreensão de suas crises e transformações e por fim construiu-se uma pedagogia centralizada na prática social, com repercussão nos mais diversos ambientes cotidianos.

Mas para que transformações ocorram, é necessária uma reorganização interna e externa da escola de modo a aproximar a educação dos cidadãos. Por esse motivo que é preciso a restruturação dos modelos educacionais atuais no que tange a atribuição de critérios racionais de pensamento crítico e consequente intervenção na realidade social, rompendo com a concepção do pensamento dominador, culminando em uma vertente de igualdade que se aproxime a igualdade prevista nos direitos humanos.

Em linhas gerais, pode-se afirmar com propriedade que o conhecimento jurídico foi socializado, através de ações educativas e integradoras aos estudantes do ensino médio, viabilizando propiciar uma maior inclusão social da juventude esclarecendo seus direitos, mas também explorando seus deveres e obrigações, não só enquanto indivíduo, mas enquanto ser social, conhecendo o ordenamento jurídico do seu país, o seu funcionamento e, principalmente, a forma de fazer uso dele e; desenvolver o ser humano em seu preparo para o exercício da cidadania e sua qualificação para o trabalho, e para a vida de um modo geral.

\section{CONSIDERAÇÕES FINAIS}

Os jovens querem aprender sobre as normas que regem as relações sociais nas quais eles estão inseridos. Percebemos que a ausência de informação cria uma aura de mistério e insegurança que inibe o questionamento e a tomada de posições.

Notamos, por outro lado, que há uma grande disposição para aprender e que faz uma diferença significativa investigar quais são os interesses dos educandos antes de submetê-los a um processo educacional.

Também percebemos que o processo educacional funciona melhor quando, aliado à exploração de temas significativos, empregando técnicas participativas, como jogos, brincadeiras e discussões.

Por outro lado, notamos que a inclusão de conteúdos jurídicos precisa de maior contextualização no universo cultural próprio dos jovens. E esse universo só pode ser ensinado por eles mesmos. Ou seja, no processo de ensinar e aprender, o educando tem que virar educador para poder transmitir ao professor as informações necessárias sobre seu mundo, seus afetos, seus interesses e seus conflitos.

Nesse processo, cria-se uma possibilidade de diálogo que não haveria se supuséssemos saber o que aqueles jovens precisam aprender. 
Direito e cidadania: inserção transversal de temas jurídicos em disciplinas escolares no ensino médio

Apesar disso, o projeto não conseguiu inserir os jovens numa discussão contínua acerca dos temas de discussão nem envolvê-los na definição das dinâmicas e atividades, nem na elaboração dos materiais de base. Isso é interessante, pois certamente existe uma mudança nos interesses ao longo dos encontros e discussões, novos temas afloram e outros, que pareciam os mais interessantes, podem ser deixados de lado. Se não houver interação, não há como saber.

A participação na escolha e construção das técnicas e dinâmicas pode aproximar ainda mais os envolvidos no processo educacional. Muitas vezes, compartilhar a execução de uma atividade cria uma atmosfera de abertura e diálogo que as atividades mais explicitamente dirigidas não conseguem proporcionar.

Por fim, o envolvimento na confecção dos próprios materiais a serem utilizados faz com que os alunos se coloquem na perspectiva de educadores, e isso os levará, essa é uma hipótese, a ver-se como educadores, como cidadãos capazes de criar e disseminar ideias, de refletir e ajudar os outros a refletir e crescer nesse processo de troca de conhecimentos.

\section{REFERÊNCIAS}

ARELARO, Lisete. A importância de Paulo Freire. Luiz Nassif Online, 30 de maio de 2015. Disponível em: http://jornalggn.com.br/noticia/a-importancia-de-paulo-freire-por-lisete-arelaro. Acesso em: 14 mar. 2017.

BRASIL. Lei $\mathrm{n}^{\circ}$ 9.394, de 20 de Dezembro de 1996. Estabelece as diretrizes e bases da educação nacional. Disponível em: http://www.planalto.gov.br/ccivil_03/leis/L9394.htm. Acesso em: 13 mar. 2017.

BRASIL. Constituição da República Federativa do Brasil de 1988. Disponível em: http://www.planalto.gov.br/ccivil_03/Constituicao/Constituicao.htm. Acesso em: 11 nov. 2017.

BRASIL. Tv escola. Documentário: John Dewey. Contemporâneo, 2004.

BRASIL. Tv escola. Documentário: Paulo Freire. Contemporâneo. 2006.

FARIAS, Maria Lígia Malta de et al. Movimento e cidadania - uma experiência do ensino do direito para alunos do PROJOVEM. Revista Eletrônica de Extensão Cidadã, João Pessoa (PB), $\quad$ v. 3, 2007.2 Disponível em: http://www.periodicos.ufpb.br/ojs/index.php/extensaocidada/article/view/1385. Acesso em: 21 dez. 2016.

FREIRE, Paulo. Pedagogia da autonomia: saberes necessários à prática educativa. São Paulo: Paz e Terra, 1983.

KANT, Imamnuel. Resposta a pergunta: Que é esclarecimento? Textos Seletos. Tradução Floriano de Sousa Fernandes. 3. ed. Petrópolis: Vozes. 2005. p. 63-71. 
Direito e cidadania: inserção transversal de temas jurídicos em disciplinas escolares no ensino médio

SILVA, José Afonso da. Curso de Direito Constitucional Positivo. 26. ed. São Paulo: Malheiros, 2005.

TEZOTO, Edenise Leite. O princípio da cidadania na constituição federal de 1988. Disponível

http://fait.revista.inf.br/imagens_arquivos/arquivos_destaque/2CaAw1nnUL9zQGT_2014-416-17-7-18.pdf. Acesso em: 14 Ago. 2017.

Recebido em: 28/06/2018

Aceito em: 29/03/2019 